\title{
Locus of interpolated activity and short-term
}

\section{memory} SHARRON S. WIKE, The University of
Kansas, Lawrence, Kans. 66044

The present study investigated the ivirerference effects on short-term memory of a 5 -sec pause following presentation of a $\mathrm{CCC}$ then recitation of six letters vs the condition of recitation of six letters and then a 5-sec pause before recall. A tape recorder was used to present the task to the $S . A$ within-Ss design was employed such that all 14 Ss underwent both conditions. For all $14 \mathrm{Ss}$, the pause-recite condition was conducive to better recall than was the recite-pause condition.

Peterson \& Peterson (1959) demonstrated rapid forgetting of a $\mathrm{CCC}$ over time intervals of a few seconds when interpolated activity was inserted between presentation and recall. In their study, the entire interyal between presentation and recall was filled, and interval length was varied. Presumably the filled interval prevented or at least reduced efficient rehearsal.

It might be expected that rehearsal just after presentation would lead to better performance than rehearsal just before recall, when the total time interval remained the same. Thus, interpolated activity at the beginning of an interval between presentation and recall should produce greater interference than interpolated activity at the end of the interval. The results of two studies, Conrad (1960) and Mortenson \& Loess (1964), bear upon this issue. Conrad interpolated a zero in an otherwise unfilled interval of $10 \mathrm{sec}$. The learning material was seven or eight digit numbers. Since interpolation of a zero just after presentation of the number did not reduce performance significantly as compared to an interpolation just before recall, he concluded that the locus of interpolated material was not important. In a similar study, Mortenson and Loess interpreted their results as offering partial support for Conrad's conclusion. In both studies, however, the groups with zero interpolated at the beginning of the interval displayed poorer performance than did the groups with zero interpolated at the end of the interval, although the differences were not significant.

The purpose of the present study was to investigate the generality of Conrad's conclusion that the locus of interpolated material was irrelevant. More precisely, the interference effects on short-term memory of a 5-sec pause following presentation of a $\mathrm{CCC}$ and then recitation of six consonants vs condition of recitation of six consonants and then a 5 -sec pause before recall were compared.

\section{METHOD}

The Ss were 14 college students, 4 males and 10 females, who were tested singly. A tape recorder provided instructions, two practice trials, the announcement that the experiment was beginning, and then administered the materials. The $S$ sat across a desk from $E$, with the tape recorder between them. The E took down S's responses as she heard them uttered.

The learning material consisted of 20 33\% Witmer syllables (Underwood \& Schulz, 1960). There were 2 practice syllables and 18 syllables in the experiment proper. The order of the CCCs was the same for all Ss. The six interpolated letters for each syllable were consonants, randomly selected. There were two recordings and Ss were assigned alternately to Recording 1 and Recording 2 . The $\mathrm{CCCs}$ in Recording 1 that were in the pause-recite condition were in the recite-pause condition on Recording 2 , and vice versa. Thus, counterbalancing of the syllables across conditions was employed.

The pause condition was approximately $5 \mathrm{sec}$ long, the presentation of the six interpolated letters took approximately $5 \mathrm{sec}$, and there were approximately $10 \mathrm{sec}$ between trials. These values were obtained by timing the intervals with a stopwatch.

The instructions to the $S$ were as follows: "This is an experiment about how people remember things. Your task is on each trial to remember the first three letters I say. As I say the letters repeat each one after me. Then I will say a string of letters. As I say each letter in the string you are to say the letter after me. When I say answer, say the first three letters I said. Sometimes there will be a pause after I say the first three letters before I say a string of letters. Sometimes there will be a pause after I say the string of letters until I say answer. Your task is to say the letters I say, one at a time, and when I say answer, give the first three letters. We will have two practice trials before we start the main part of the experiment."
If, on the first practice trial, the $S$ grouped his responses instead of repeating each letter singly, the recorder was shut off, and $S$ was instructed again to repeat each letter as he heard it. By the second practice trial, all Ss were repeating correctly. The letters that $S$ repeated were not always the same letters that were presented. Sometimes, for example, $M$ and $\mathrm{N}$ or $\mathrm{S}$ and $\mathrm{X}$ were given in place of one another. Nothing was said to $S$ if he gave an incorrect letter of the $\mathrm{CCC}$ or the interpolated letters. Nothing was said by $\mathrm{E}$ to $S$ after the experiment proper had begun.

\section{RESULTS AND DISCUSSION}

For all 14 Ss, more syllables were recalled under the pause-recite condition than under the recite-pause condition. By the sign test (Walker \& Lev, 1953), the probability of 14 out of 14 results being in one direction due to chance is less than .001 . In the pause-recite condition, the mean number of items recalled was 5.79 , or $64 \%$. In the recite-pause condition, the mean number of items recalled was 3.21 , or $36 \%$.

The results argue strongly that the locus of interpolated activity may be important in short-term memory experiments. The results of the present study are not in agreement with those reported by Conrad or Mortenson and Loess. The reason for this disagreement is not readily apparent since the three studies differed in a number of ways: (1) the type of learning material, i.e., numbers vs letters, (2) the length of the learning material, i.e., three vs six units, (3) the type of interpolated material, i.e., a zero vs consonants, and (4) the length of the interpolated material, i.e., one unit vs six units. Further experiments, varying these factors, are necessary in order to detect the factors responsible for the disagreement among the results. Finally, it should be noted that the disagreement among the three studies concerns significance only; in all three studies, interpolated activity right after learning lead to greater interference than did interpolated activity prior to recall.

\section{REFERENCES}

CONRAD, R. Very brief delay of immediate memory. Quarterly Journal of Experimental Psychology, 1960, 12, 45-47.

MORTENSON, J., \& LOESS, H. Effect of very brief interpolated activity on short-term retention. Perceptual \& Motor Skills, 1964, 18, 797-803.

PETERSON, L. R., \& PETERSON, M. J. Short-term retention of individual verbal items. Journal of Experimental Psychology, $1959,57,193-198$.

UNDERWOOD, B. J., \& SCHULTZ, R. W. Meaningfulness and verbal learning. Philadelphia: Lippincott, 1953.

WALKER, H. M., \& LEV, J. Statistical inference. New York: Holt, 1953. 